SAFETY RULES FOR USE IN CHEMICAL WORKS : PART 1-MODEL RULES

(Issued by the Association of British Chemical Manufacturers. London. 1947. Third Edition. Price 7s. 6d.)

This book presents a summary of the precautions to be taken in working with dangerous materials, and also much information on the principles of good management. The Council of the Association regards it as essential that safe working conditions shall keep pace with technical improvements, in order that the industry shall offer attractive and congenial employment. The rules incorporate the various changes in legislation, and it is stressed that, although they are divided into sections for convenience, they must be read and observed as a whole. The necessary references to the Factories Act and relevant regulations are given in the text of the rules.

Section I sets out general rules for the conduct of work in factories and the establishment and supervision of working conditions. It is highly desirable that all these rules should be adopted in new chemical works and plants and in all works which are being rebuilt or extended. Sections II, III, IV, and V set out rules for the design; operation, and maintenance of plant involving risks from fire and explosion, gas, fume, or dust, and corrosive and deleterious substances. The scope of the rules is comprehensive. Section VI gives rules for fire protection.

The provision of an industrial health service is covered by the rules in Section VII. It is recommended or required that a medical officer should be appointed and that he should be given the fullest information concerning the hazards to be encountered. This recommendation, together with pre-employment and periodic medical examinations and the provision of medical departments, with nurses and adequate numbers of well-trained firstaid personnel, constitutes the basis of a medical service in industry.

Rules covering the general provisions for welfare are given in Section VIII, and special rules concerning the employment of women and young persons in Section IX.

The rules and information given in this book are the result of close co-operation and consultation in industry and are obviously based on practical experience. Their importance cannot be overemphasized and the book is wholly excellent and welcome.

A. T. J.

\section{PHYSIOLOGY OF MAN IN THE DESERT}

By E. F. Adolph and Associates

(Dept. of Physiology, University of Rochester. Interscience Publishers, Inc.; New York. 1947. Pp. xiii+ 357, 184 figures. Price 39s.)

This stimulating book contains investigations which were carried out by the Desert Unit of Rochester University, partly in the hot room, partly in the Colorado Desert. An enormous amount of experimental data has been compiled by Adolph and his nine associates. Their main conclusion is that life and efficiency in the hot climate depends on the degree of dehydration, which is the overriding factor. The water loss may be 11 litres per day, of which amount ninetenths may be expended as sweat. If 5 or 10 per cent. of the body weight is lost by dehydration, the loss can be made good quickly and without any lasting ill effects. If the loss of water reaches 20 per cent. it may have done irreversible harm. The water loss is not shared equally by all parts of the body: the blood serum concentrates as much as the whole body. This causes a decrease of the circulating blood volume, the influence of which is severe, as the circulation has to maintain at the same time an abundant flow of blood for cooling purposes. An accelerated pulse rate and increased body temperature are signs of the circulatory strain. An important practical point is the question of " voluntary dehydration." The thirst is usually not strong enough to induce frequent drinking of sufficient amounts, and a chronic state of mild dehydration is therefore common. This condition often impairs working efficiency without being recognized as the real cause. "When fully hydrated, man cheerfully does tasks which he finds distasteful if he is moderately dehydrated and consequently in low spirits." Acclimatization to heat is possible, but acclimatization to dehydration has not been proved. Little attention is paid to chloride metabolism, although here also one might expect changes caused by adaptation.

A number of practical conclusions are drawn which concern clothing, food, and water requirements. They will be of importance not only to future desert rats, but also to those who are responsible for the health of workers in hot environments. The book will be of value to all those who are interested in applied physiology.

H. $\boldsymbol{H}$.

\section{DEMONSTRATIONS OF PHYSICAL SIGNS IN CLINICAL SURGERY}

By Hamilton Bailey, F.R.C.S., etc.

John Wright and Sons. Bristol. 1948. Pp. 100. Price 8s. 6d.)

Owing to difficulties of printing etc. this edition of Mr. Hamilton Bailey's well-known book is appearing in four parts with a paper cover. It is a pity that this method of publication has been necessary, as the unity of the work is destroyed and the paper cover is unlikely to last long in libraries or in a student's hand.

The first part includes chapters on the basic principles of clinical examination and then proceeds to a description of conditions that affect the face, mouth, and head. The illustrations, on which the strength of the book lies, are for the most part excellent and show very clearly the points which Mr. Bailey is anxious to stress. The text is clear and concise, and leaves the student in little doubt as to the meaning.

It is to be hoped that the other parts of this work will soon be published, since the whole work will be of considerable more value than each individual part. This book is very strongly recommended to medical students because they will find clearly and concisely described the essential physical signs of many conditions they will meet with in the out-patient department and in general practice.

E.C.B.B.

\section{CATALOGUE OF MEDICAL FILMS}

(Compiled by The Royal Society of Medicine and the Scientific Film Association. Aslib. London. 1948. Pp. 125. Price 7s. 6d.)

This is a valuable little publication which, as its name implies, gives a list of the medical films available at the present time. It does more than this, however, because it gives a brief account of two hundred of them; and also gives the running time and information as to whether they are sound or silent, colour or monochrome. To those who use films it should be a very useful work.

K. M. A.P. 